\title{
Biosignature False Positives
}

\author{
Chester E. Harman and Shawn Domagal-Goldman
}

\section{Contents}

Leave No Stone Unturned . . . . . . . . . . . . . . . . . . . . . . . . . . . . 2

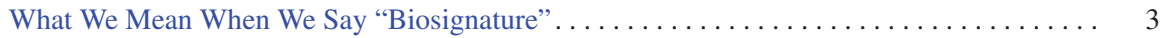

A Brief List of Biosignatures. . . . . . . . . . . . . . . . . . . . . . . . . . . . 4

What We Mean When We Say "False Positive"........................ 8

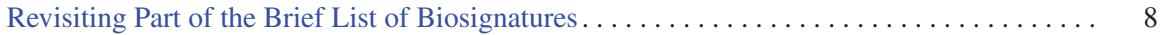

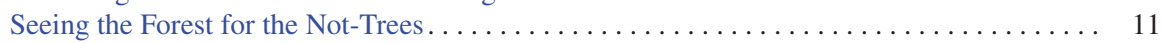

Where the Rubber Meets the Road .............................. 13

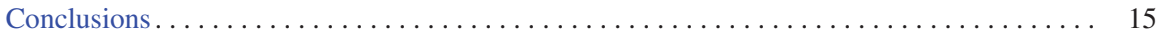

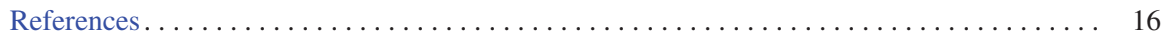

\section{Abstract \\ In our search for life - whether within the earliest part of Earth's geologic record, on planets within our solar system such Mars, or especially for extrasolar}

C. E. Harman ( $\square)$

NASA Goddard Institute for Space Studies, New York, NY, USA

Department of Applied Physics and Applied Mathematics, Columbia University, New York, NY, USA

NASA Astrobiology Institute-Virtual Planetary Laboratory, Seattle, USA

e-mail: chester.e.harman@nasa.gov

S. Domagal-Goldman

Planetary Systems Laboratory, NASA Goddard Space Flight Center, Greenbelt, MD, USA

NASA Astrobiology Institute-Virtual Planetary Laboratory, Seattle, USA

Sellers Exoplanets Environments Collaboration, NASA Goddard Space Flight Center, Greenbelt, MD, USA

e-mail: shawn.goldman@nasa.gov

(C) This is a U.S. Government work and not under copyright protection in the US;

foreign copyright protection may apply 2018

H. J. Deeg, J. A. Belmonte (eds.), Handbook of Exoplanets, https://doi.org/10.1007/978-3-319-30648-3_71-1 
planets - we must infer the presence of life from its impact on the local or global environment. These "biosignatures," often identified from the known influence of terrestrial organisms on the Earth's atmosphere and surface, could be misdiagnosed when we apply them to alien worlds. The so-called false positives may occur when another process or suite of processes masks or mimics a biosignature. Here, we examine several leading biosignatures, then introduce potential false positives for these signals, and finally discuss methods to discriminate between the two using current and future detection technologies. We conclude that it is the astrobiology community's responsibility to thoroughly exhaust all possibilities before we resort to "life" as an explanation.

\section{Leave No Stone Unturned}

The existence of worlds beyond Earth that are capable of supporting life has been the subject of fierce debate throughout history. Within the last 30 years, however, we have moved from philosophy to science. The first observations of an extrasolar planet (or exoplanet) to ultimately be confirmed were made by Campbell et al. (1988), but its presence was not immediately confirmed. The first confirmed exoplanet discovery was a planet orbiting a pulsar (Wolszczan and Frail 1992); the first confirmed exoplanet orbiting a main sequence star was discovered a few years later (Mayor and Queloz 1995). In the last 10 years, NASA's Kepler Space Telescope has added thousands of new data points to a rapidly growing list of exoplanets (Twicken et al. 2016), including Earth-sized planets within the habitable zones of their respective host stars (e.g., Quintana et al. 2014). With the end of Kepler's primary mission in 2013, the subsequent K2 mission and ground-based telescopes have continued making landmark discoveries. These include relatively nearby exoplanets that are potentially amenable to transit spectroscopy observations in the next decade, including the seven-planet system orbiting TRAPPIST-1 (Gillon et al. 2016) and terrestrial planets in the habitable zones of both Proxima Centauri (Anglada-Escudé et al. 2016) and LHS 1140 (Dittmann et al. 2017). But the question still remains: do any of these worlds harbor life? Perhaps more importantly, will we be able to tell?

With the design and construction of increasingly powerful telescopes, we will gain the ability to characterize the atmospheres and eventually the surfaces of an increasing diversity of potentially Earth-like worlds. Such observations will begin with the James Webb Space Telescope (JWST), which has the ability to obtain transit and transmission spectra of exoplanets. JWST will be best equipped to obtain such data for larger worlds, but its sensitivities may allow it to detect the largest absorption features on a small number of nearby Earth-like worlds in orbit around cool, low-mass stars (Deming et al. 2009). Greater sensitivities for this kind of observation - likely fine enough for biosignature searches - will be enabled by extremely large ground-based telescopes such at the Giant Magellan Telescope (GMT), the European-Extremely Large Telescope (E-ELT), and the Thirty Meter Telescope (TMT) (Kawahara et al. 2012; Snellen et al. 2013, 2015; Rodler and 
López-Morales 2014; Lovis et al. 2017). A second generation of instruments for these telescopes may include coronagraphs that could directly image such worlds and obtain reflected-light spectroscopy which would allow assessment of deeper layers of the exoplanet's atmosphere. However, the ground-based observations will likely be limited to rocky planets in the habitable zones of low-mass stars with intense high-energy radiation (Garcia-Sage et al. 2017).

Observations of rocky planets in the habitable zones of more Sun-like stars will likely require space-based telescopes that are designed from the start with characterization of rocky worlds in mind. Two such mission concepts are currently being studied: the habitable exoplanet observatory (HabEx) (Mennesson and Mawet 2016) and the large ultraviolet/optical/infrared telescope (LUVOIR) (France et al. 2015; Crooke et al. 2016). Both of these missions, as well as the Origins Space Telescope (Cooray et al. 2017), and the Lynx X-ray Observatory (Gaskin et al. 2017; Branduardi-Raymont et al. 2017) would conduct transit spectroscopy at complementary wavelengths to the targets ground-based facilities may observe. However, only HabEx and LUVOIR will be able to conduct observations of rocky planets in orbit around Sun-like stars.

As these ideas become reality, we can imagine an ever-expanding cloud of stars and planets with an increasing diversity of properties, all carefully observed and categorized. Information about the atmospheres of these planets could hold the key to finding life on these worlds. But first, we have to understand how to observe the impact life has on its environment, and the ways environments could generate similar observable features.

\section{What We Mean When We Say "Biosignature"}

When trying to detect life on planets orbiting other stars, the direct observation of life (e.g., focusing on a single tree in an alien forest, or seeing an alien, or having the alien shake our hand) is incredibly unlikely - They might not even have hands to shake, which would make it impossible, in fact. Within the next several decades, however, it may be possible to observe indirect evidence for that life using the socalled biosignatures. A biosignature is any measurement or observation that requires a biological origin to explain what is being measured or observed (Des Marais and Walter 1999; Des Marais et al. 2008; Schwieterman et al. 2017). This would include such indicators as dinosaur fossils, empty candy wrappers, the green haze of a forest too far away to make out the individual trees, or the oxygen we're all breathing. Each of these observations provides indirect evidence, of varying strength, for the presence of extant (or extinct) life.

Biosignatures can be divided into two broad categories: technological (e.g., the candy wrapper) and biological (e.g., oxygen). SETI, in partnership with a number of international groups, has made great strides in monitoring an increasing number of the closest stars to Earth for technological biosignatures (or "technosignatures") (e.g., Tarter 2001; Welch et al. 2009; Abeysekara et al. 2016). We will focus here on the biological counterpart to life detection (however, we will briefly touch on 
technosignatures again when we define "false positive"). Under the broad category of "biosignature," we can imagine that there are a multitude of observations we can make within our solar system but just a few features that would be observable across interstellar distances. For example, we can imagine (as many of us did when we were younger) going on a hike and stumbling over the fossilized remains of some fantastical beast. We would then carefully examine the fossil and with expert opinions identify what it was like while it was alive. Dinosaur fossils are harder to dig up, however, across the vastness of space. Even with the possibility of traveling to Mars and digging through eons of sedimentary rocks, we are met with the harsh reality that life elsewhere may not share the same complex evolutionary history as life on Earth, preventing us from finding Martian dinosaurs (or other multicellular creatures) that leave clear fossils in the rock record. That said, the elements and conditions that led to life here on Earth are common, and we should expect simple life, at least, to be common throughout the universe (Meadows 2017). The question then becomes: what mark does simple life leave on its global environment that might be seen across interstellar distances?

\section{A Brief List of Biosignatures}

We begin by using the Earth as a template in our search for life elsewhere. The abundance of single-celled organisms throughout Earth's history is recorded in the geologic record and in the atmosphere, and while multicellular organisms have come to dominate the surface today, continents may once have been controlled solely by extensive colonies of microbes (Rye and Holland 2000; Watanabe et al. 2000). The leading contender for the earliest evidence of life stems from the 3.7-Gya (billionyear-old) Isua supracrustal belt in Western Greenland, which features isotopically light graphite, indicating a biological origin (Rosing 1999; Ohtomo et al. 2014). Other possible indicators for life on the early Earth include $>3.85$-Gya carbon inclusions contained within apatite mineral grains in the Akilia island banded iron formation (Mojzsis et al. 1996) and putative microbial filament fossils captured in the 3.6-Gya Apex Chert (Schopf et al. 2002) (Fig. 1). Suggested evidence of early life extends beyond Earth, with reports of carbonate globules and pyrite consistent with biology contained in the Allan Hills meteorite ALH84001 (McKay et al. 1996; Thomas-Keptra et al. 2010). These examples highlight our geological search for signs of life, but even if these signals were solidly unambiguous, this approach is untenable (at least with modern technology) for our search for life among the stars. In this case, we must look to ways in which life has made an appreciable impact on the globe.

Biological processes that have globally modified the Earth through time, and that could potentially appear on other worlds, largely produce either (or possibly both) surface or atmospheric signals. The reader is directed to Schwieterman et al. (2017) for an in-depth review of the catalog of potential atmospheric and surface biosignatures, as well as to the chapters "Atmospheric Biosignatures" (Grenfell), "The Detectability of Earth's Biosignatures Across Time" (Pallé), and "Earth: 


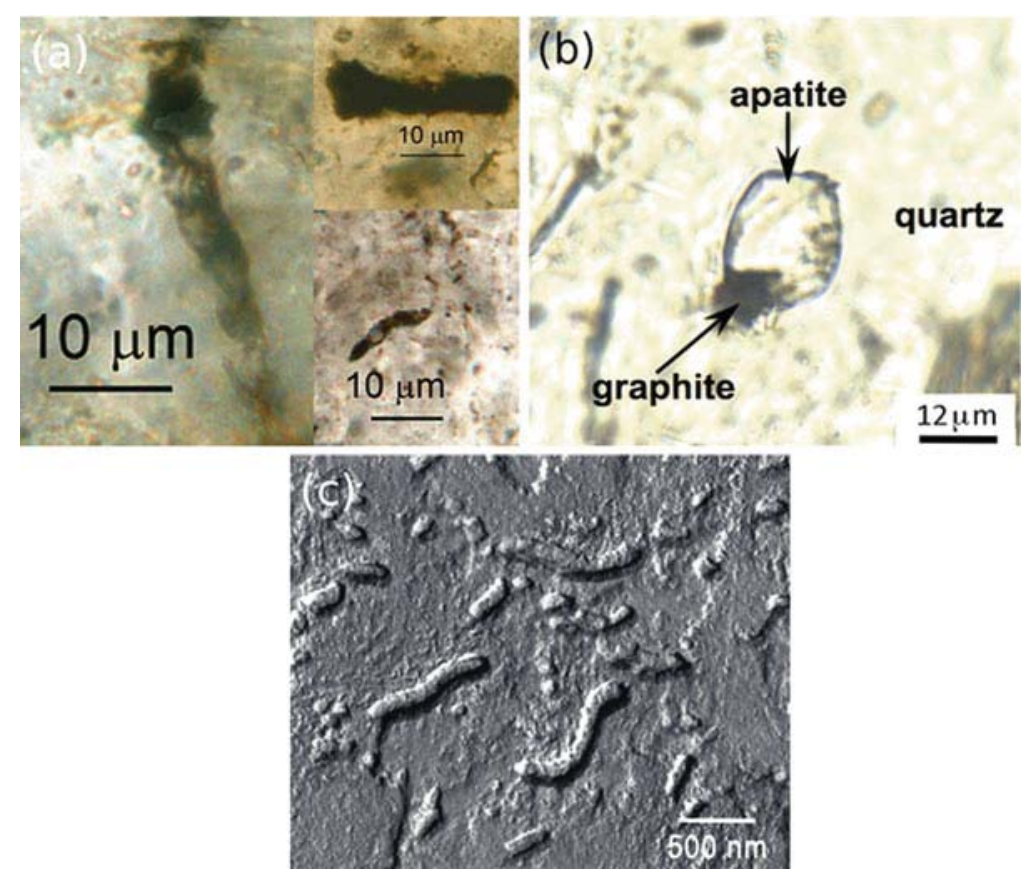

Fig. 1 (a) Optical photomicrographs of Apex Chert inclusions (Image modified from Project 3D 2015 NAI Annual Science Report); (b) images of apatite crystals from a banded iron formation in the Nuvvuagittuq (Isua) supracrustal belt on Akilia island (Image from Papineau 2010); (c) transmission electron microscopy of a cast of ALH84001, purported to show microbial fossils. (Image ARC-1996-AC96-0345-11, JSC/ARC)

Atmospheric Evolution of a Habitable Planet" (Olson et al.) in this volume. Here, we will highlight just a few.

Molecular oxygen $\left(\mathrm{O}_{2}\right)$, which makes up $21 \%$ of the modern Earth's atmosphere, is a direct consequence of oxygenic photosynthesis coupled with organic carbon burial (Kasting and Canfield 2012):

$$
\mathrm{H}_{2} \mathrm{O}^{\text {liquid }}+\mathrm{CO}_{2}{ }^{\text {dissolved }} \rightarrow \mathrm{CH}_{2} \mathrm{O}^{\text {solid }}+\mathrm{O}_{2}{ }^{\text {dissolved }}
$$

$\mathrm{O}_{2}$ represents a fantastic biosignature due to its high abundance in the Earth's atmosphere, its known biological origin, its distinct spectral fingerprints, and its lack of substantial abiotic sources on Earth (Meadows 2017; Meadows et al. 2017). Oxygen-producing life like cyanobacteria (and relative latecomers such as grasses and trees) takes in water $\left(\mathrm{H}_{2} \mathrm{O}\right)$ and carbon dioxide $\left(\mathrm{CO}_{2}\right)$ and then "fixes" the carbon (represented as $\mathrm{CH}_{2} \mathrm{O}$ above), making it accessible for other biological processes. The $\mathrm{O}_{2}$ is then free to accumulate in the water column (where cyanobacteria live) and ultimately exsolve into the atmosphere. While the constraints on when oxygenic photosynthesis evolved are currently obscured by 
the sparse geological record, there is strong evidence that it did arise by the midArchean (>2.5 Gya) (Farquhar et al. 2011). This is when, due to the prevalence of this metabolism, oxygen concentrations rose to modest concentrations $\left(\sim 0.02 \% \mathrm{O}_{2}\right.$ by volume, or $\sim 0.1 \%$ the present atmospheric level or PAL) (Planavsky et al. 2014). This event is often referred to as the Great Oxidation Event (GOE). Oxygen levels rose again - to near-modern concentrations - in the Neoproterozoic $\sim 800$ Mya (Kump 2008; Lyons et al. 2014). Following the GOE, $\mathrm{O}_{2}$ levels were likely high enough to give rise to a thick ozone $\left(\mathrm{O}_{3}\right)$ layer which would be potentially detectable with future space telescopes (Segura et al. 2003). Together, $\mathrm{O}_{2}$ and its proxy $\mathrm{O}_{3}$ represent arguably the strongest individual biosignature gas, clearly indicating the presence of a substantial oxygen-producing biosphere, as compared to a world without one (Kasting et al. 1984; Kasting 1995; Segura et al. 2003, 2007; DomagalGoldman et al. 2014). Several extensive reviews of $\mathrm{O}_{2}$ as a biosignature are available (Meadows 2017; Meadows et al. 2017). Another potential biosignature gas is methane $\left(\mathrm{CH}_{4}\right)$ (Des Marais et al. 2002), which is produced under low-oxygen conditions by either the disproportionation of acetic acid $\left(\mathrm{CH}_{3} \mathrm{COOH}\right)$ into $\mathrm{CH}_{4}$ and $\mathrm{CO}_{2}$ (Pilcher 2003; Schwieterman et al. 2017):

$$
\mathrm{CH}_{3} \mathrm{COOH} \rightarrow \mathrm{CH}_{4}+\mathrm{CO}_{2}
$$

or by reducing $\mathrm{CO}_{2}$ using molecular hydrogen $\left(\mathrm{H}_{2}\right)$ :

$$
\mathrm{CO}_{2}+4 \mathrm{H}_{2} \rightarrow \mathrm{CH}_{4}+2 \mathrm{H}_{2} \mathrm{O}
$$

On the modern Earth, atmospheric $\mathrm{CH}_{4}$ is a trace gas at $\sim 1.7$ parts per million (ppm) and is largely biological in origin (e.g., Cicerone and Oremland 1988; Kirschke et al. 2013). But earlier in Earth's history, $\mathrm{CH}_{4}$ concentrations may have been much higher, producing much stronger features in the Earth's spectrum (Sagan et al. 1993; Pavlov et al. 2003; Kharecha et al. 2005; Kaltenegger et al. 2007; Gebauer et al. 2017). It would have been even more detectable on similar planets around different stellar host types (Segura et al. 2003, 2005; Rugheimer et al. 2013, 2015). Additionally, a high $\mathrm{CH}_{4}: \mathrm{CO}_{2}$ ratio $(>0.1)$ may result in an observable photochemical haze (Haqq-Misra et al. 2008; Harman et al. 2013; Arney et al. 2016), consistent with geochemical evidence for the presence of a haze during several epochs in Earth's history (Domagal-Goldman et al. 2008; Zerkle et al. 2012; Izon et al. 2017).

Nitrous oxide $\left(\mathrm{N}_{2} \mathrm{O}\right)$ is emitted by life when $\mathrm{N}_{2} \mathrm{O}$ escapes during denitrification (the reduction of nitrate, $\mathrm{NO}_{3}{ }^{-}$, back to atmospheric dinitrogen, $\mathrm{N}_{2}: \mathrm{NO}_{3}{ }^{-} \rightarrow \mathrm{NO}_{2}{ }^{-}$ $\rightarrow \mathrm{NO}+\mathrm{N}_{2} \mathrm{O} \rightarrow \mathrm{N}_{2}$ ) (Schwieterman et al. 2017). There are only trace amounts of $\mathrm{N}_{2} \mathrm{O}$ in the modern atmosphere, ranging from $\sim 270$ parts per billion in the preindustrial to $\sim 327 \mathrm{ppb}$ today (Warner et al. 2016). Like $\mathrm{CH}_{4}, \mathrm{~N}_{2} \mathrm{O}$ concentrations could have been higher earlier in Earth's history (Buick 2007; Roberson et al. 2011) and respond to differences in host star radiation (Segura et al. 2005; Rugheimer et al. 2015). 


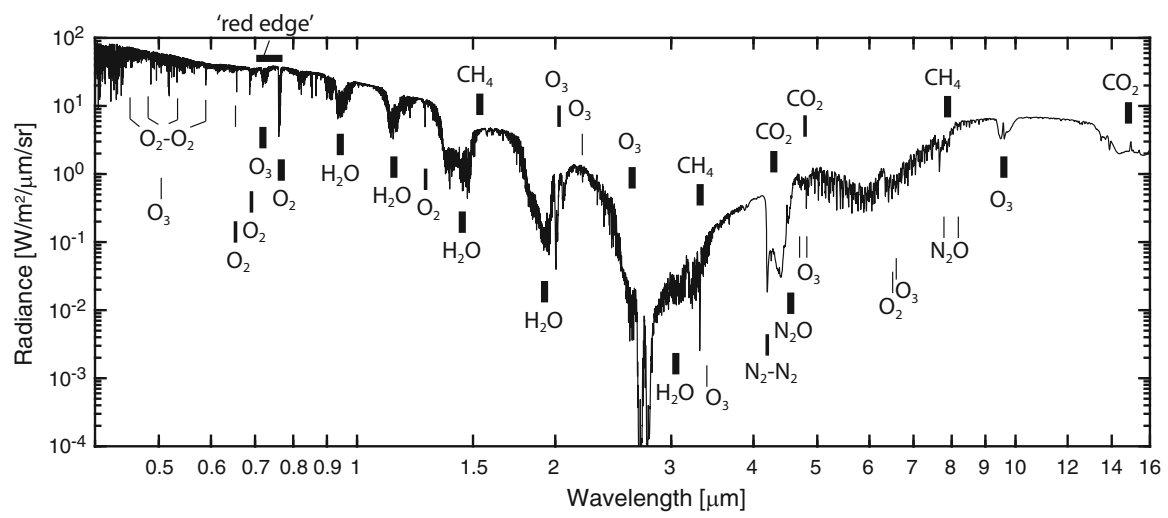

Fig. 2 Simulated spectrum of the Earth matching EPOXI observations for the 24-h average (May 29, 2008) using the 3D Earth model (Robinson et al. 2011). Spectral fingerprints for relevant biosignatures, and their discriminator partners, are highlighted, with the size of the line giving a general indication of the strength of the biosignature relative to its strength at other wavelengths

Besides examining the composition of the atmosphere, we can imagine looking for clues for the presence of life from the wavelength-dependent characterization of a planet's surface. For example, the "red edge" is a distinctive feature at $0.7 \mu \mathrm{m}$, as chlorophyll stops absorbing outside the visible wavelength region (Gates et al. 1965); this can be seen in reflectance spectra of the modern Earth (Sagan et al. 1993) and Earthshine (Seager et al. 2005; Turnbull et al. 2006). Similarly, other biotic pigments (both photosynthetic and nonphotosynthetic) could be detectable, if they accumulate across a significant portion of a planet (Hegde et al. 2015; Schwieterman et al. 2015a, 2017; see also the chapter - "Surface and Temporal Biosignatures" by Schwieterman in this volume).

We can better constrain the life detection problem by considering looking for multiple features, either biosignatures or environmental characteristics, that strengthen our confidence that a biosignature is due to life. For example, $\mathrm{CH}_{4}$ or $\mathrm{N}_{2} \mathrm{O}$ alongside $\mathrm{O}_{2}$ or $\mathrm{O}_{3}$ is often cited as the "gold standard" of biosignatures (e.g., Hitchcock and Lovelock 1967; Meadows 2017), as these species would react and exhaust the less abundant gas rapidly without a continuous source (Lippincott et al. 1967; Lovelock and Kaplan 1975; Sagan et al. 1993; Krissansen-Totton et al. 2016). More broadly, a detection of more than one biosignature simultaneously would potentially provide stronger evidence than any one biosignature (Fig. 2). 


\section{What We Mean When We Say "False Positive"}

In our list of biosignatures, we have included examples from modern and ancient Earth, including speculation as to their behavior on planets orbiting other types of stars. A "false positive" is when a measurement or observation of a potential biosignature could be overlapped (or a discriminating feature obscured) by one or more non-biological phenomena. To say it differently, any abiotic process that superficially resembles a biological process would qualify as a false positive, for example, oxygen derived from photochemical processes instead of oxygenic photosynthesis. As a brief aside, there is also the issue of false negatives, where life may exist, but would be undetectable (Cockell 2014; Reinhard et al. 2017; Olson et al., this volume). Much like the false-positive case, as we discuss below, it could be resolved with additional information.

To return to one of our first examples, let us say we are looking for dinosaur fossils. As non-experts, a false positive could be that we find a strange-looking rock - say, Roccia dell'Elefante (Elephant Rock) on the northern coast of Sardinia, Italy (Fig. 3). Without further information, we would be stymied in our attempts to verify whether or not it was, in fact, a fossilized elephant (or dinosaur, for that matter - we were looking for dinosaurs). We could examine it more closely; call in an expert to determine the mineralogy, the local geology, and its history; and come to the conclusion that Elephant Rock is, in fact, a rock. Determining that this was a rock, and not a fossil, involved much more than just identifying the elephantlike shape of the rock. Similarly, early SETI attempts often met with false alarm signals (see Shostak and Oliver (2000) for two brief examples), which has driven innovations in search strategies and technology (e.g., Tarter et al. 2010). This leads to an important point: regardless of the strength of the biosignature, or the presence or absence of documented false positives associated with it, every measurement requires contextual information to frame it. And in the cases where false positives could potentially occur, it becomes critical that we (1) work to "inoculate the public against grossly inaccurate information" (Shostak and Oliver 2000) and (2) reinforce all observations with the necessary measurements to discriminate true from false positives. Which brings us back to the biosignatures we have listed above - do any of these have false positives, or fail to remain biosignatures with the addition of new analyses?

\section{Revisiting Part of the Brief List of Biosignatures}

For exoplanets, there are currently a limited number of ways to potentially detect life, but there is a growing list of potential mechanisms capable of generating false positives (Schwieterman et al. 2017). Within the last few years, $\mathrm{O}_{2}$ has faced increased scrutiny due to its position as the forerunner biosignature, and as a result, several authors have shown that worlds without life, under some circumstances, could accumulate $\mathrm{O}_{2}$-rich atmospheres. The reader is directed to Meadows (2017) 

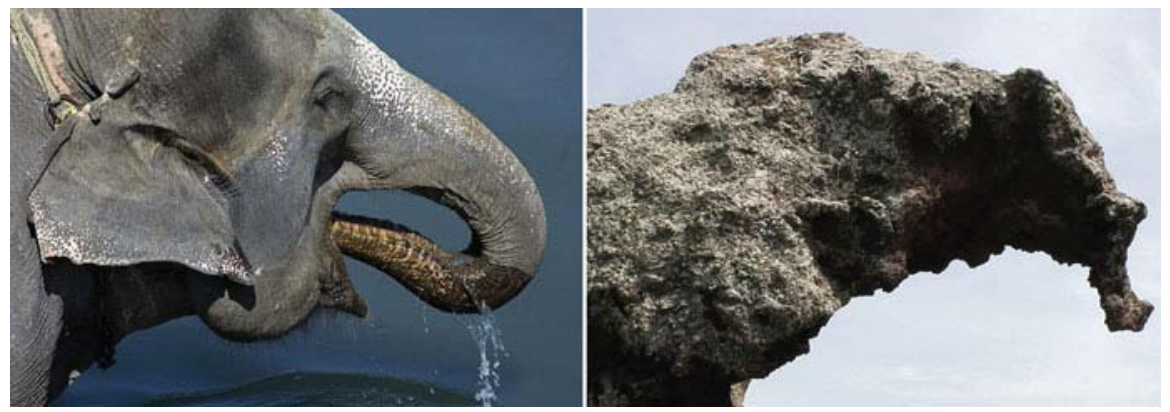

Fig. 3 Left, elephant drinking water (Image by Barbara Piuma from Argentina - Elephant bath, CC BY-SA 2.0, https://commons. wikimedia.org/w/index.php?curid=5310145); Right, Roccia dell'Elefante in Castelsardo, Sardinia, Italy (Image by Francesco Canu - Elephant Rock, CC BY-SA 3.0, https://commons.wikimedia.org/wiki/File:Elephant_Rock.JPG). Note the striking resemblance

and Meadows et al. (2017) for a more detailed analysis of false positives associated with $\mathrm{O}_{2}$. For example, cold, dry planets with $\mathrm{CO}_{2}$-rich atmospheres could build up detectable amounts of $\mathrm{O}_{2}$, derived from $\mathrm{CO}_{2}$ photolysis $\left(\mathrm{CO}_{2}+\mathrm{h} v \rightarrow \mathrm{CO}\right.$ $+\mathrm{O}$, where $\mathrm{h} v$ is a photon) followed by the recombination of two $\mathrm{O}$ atoms into $\mathrm{O}_{2}$ (Kasting 1997, 2010; Gao et al. 2015). Additionally, planets orbiting smaller stars experience lower near-ultraviolet (NUV) radiation fluxes than planets orbiting Sun-like stars, which leads to less water vapor photolysis in their atmospheres. Even with temperate surface conditions, a $\mathrm{CO}_{2}$-dominated atmosphere can build up appreciable amounts of $\mathrm{O}_{2}$ and $\mathrm{O}_{3}$, again a result of $\mathrm{CO}_{2}$ photolysis (Tian et al. 2014; Harman et al. 2015). The photochemical source of $\mathrm{O}_{2}$ in all these cases is dependent on limiting the catalytic recombination of $\mathrm{CO}$ and $\mathrm{O}$, the products of $\mathrm{CO}_{2}$ photolysis, through water vapor photolysis:

$$
\mathrm{H}_{2} \mathrm{O}+\mathrm{h} v \rightarrow \mathrm{OH}+\mathrm{H}
$$

followed by

$$
\begin{array}{r}
\mathrm{CO}+\mathrm{OH} \rightarrow \mathrm{CO}_{2}+\mathrm{H} \\
\mathrm{O}_{2}+\mathrm{H}+\mathrm{M} \rightarrow \mathrm{HO}_{2}+\mathrm{M} \\
\mathrm{HO}_{2}+\mathrm{O} \rightarrow \mathrm{O}_{2}+\mathrm{OH} \\
\hline \text { net }: \mathrm{CO}+\mathrm{O} \rightarrow \mathrm{CO}_{2}
\end{array}
$$

For dry, cold planets, the lack of water vapor inhibits this cycle (Gao et al. 2015); for planets around $\mathrm{M}$ dwarf host stars, slower water vapor photolysis achieves the same effect (Harman et al. 2015). In both cases, the accumulation of $\mathrm{O}_{2}$ to detectable concentrations is governed predominantly by photochemistry and climate. 
Two other scenarios can lead to the buildup of $\mathrm{O}_{2}$, via loss of atomic hydrogen $(\mathrm{H})$ to space. This causes an irreversible oxidation of the atmosphere. One way to achieve this is through a runaway greenhouse, where a planet sufficiently close to its host star heats up enough to evaporate the surface ocean (Kasting et al. 1993; Schindler and Kasting 2000; Kopparapu et al. 2013). Water vapor is photolyzed $\left(\mathrm{H}_{2} \mathrm{O}+\mathrm{h} v \rightarrow \mathrm{OH}+\mathrm{H}\right)$, and the light $\mathrm{H}$ is lost to space. Conventionally, the habitable zone is defined on the inner edge by the runaway greenhouse (Kopparapu et al. 2013), but the smallest stars (very late $\mathbf{M}$ dwarfs specifically) have very long superluminous phases before they evolve onto the main sequence. This means planets within the main sequence habitable zone for these stars were located interior to the runaway greenhouse for the pre-main sequence phase (Luger and Barnes 2015). This pre-main sequence time is short for Sun-like stars (on the order of a few tens of millions of years or less) but can be up to a billion years for the smallest stars (Baraffe et al. 1998). This is sufficient to potentially drive the loss of several Earth oceans of water - leaving hundreds to thousands of bars of $\mathrm{O}_{2}$ behind (Luger and Barnes 2015). The other water loss process is much gentler and affects those planets that lack sufficient $\mathrm{N}_{2}$ or $\mathrm{O}_{2}$ in their atmospheres (Wordsworth and Pierrehumbert 2014). These planets would have temperate climates, but without cold traps for water, allowing high water vapor content in the upper atmosphere and gradual loss of $\mathrm{H}$ to space through water vapor photolysis. Atmospheric loss would shut off once $\sim 0.02-0.2$ bars of $\mathrm{O}_{2}$ had accumulated - very close to the amount of $\mathrm{O}_{2}$ in the modern Earth's atmosphere (Wordsworth and Pierrehumbert 2014). All of these processes could drive the accumulation of appreciable, and potentially detectable, atmospheric concentrations of $\mathrm{O}_{2}$.

$\mathrm{N}_{2} \mathrm{O}$ is another strong biosignature gas, with few known abiotic mechanisms for formation. There is a tiny abiotic production route for $\mathrm{N}_{2} \mathrm{O}$ through lightning in the modern Earth's atmosphere (e.g., $\mathrm{N}_{2}+\mathrm{O}_{2} \rightarrow 2 \mathrm{NO}$ ) (Schumann and Huntrieser 2007), as well as limited $\mathrm{N}_{2} \mathrm{O}$ production in hypersaline ponds (Samarkin et al. 2010). But the ultraviolet (UV) environment for planets around $M$ dwarfs lowers the fluxes necessary to enhance the abundances of biogenic $\mathrm{N}_{2} \mathrm{O}$ (Segura et al. 2005), and the same works for $\mathrm{N}_{2} \mathrm{O}$ from lightning (Navarro et al. 2014). It has also been suggested that the XUV flux around active $\mathrm{M}$ dwarfs can also split the $\mathrm{N}_{2}$ triplebond efficiently, leading to $\mathrm{N}_{2} \mathrm{O}$ accumulation (Airapetian et al. 2016). However, the reported abiotic $\mathrm{N}_{2} \mathrm{O}$ concentrations were still too low (varying from $0.02 \mathrm{ppm}$ at the surface to $3 \mathrm{ppm}$ in the upper atmosphere) and so are likely undetectable (Navarro et al. 2014). Note that while this means the tested scenario fails to generate a false positive, there could be secondary effects not considered that may exacerbate the buildup of $\mathrm{N}_{2} \mathrm{O}$.

The false-positive mechanism for $\mathrm{CH}_{4}$ is much more straightforward than those for $\mathrm{O}_{2}$ and $\mathrm{N}_{2} \mathrm{O}$. While life produces the overwhelming majority ( $>99 \%$ ) of $\mathrm{CH}_{4}$ in the Earth's atmosphere (Kasting 2005), some geologic processes emit small amounts of $\mathrm{CH}_{4}$ (e.g., Etiope and Sherwood Lollar 2013). Additionally, serpentinization, the hydration of ultramafic (e.g., basaltic) seafloor, releases substantial amounts of $\mathrm{H}_{2}$, which can (in the presence of $\mathrm{CO}_{2}$ ) result in $\mathrm{CH}_{4}$ production (Guzmán-Marmolejo et al. 2013; Etiope and Sherwood Lollar 2013). However, 
there is wide disagreement on the fraction of $\mathrm{CH}_{4}$ from serpentinizing systems on Earth that is biological, rather than geochemical in nature; this is an important area of future work for this false-positive source. As an edge case, Titan, the largest moon of Saturn, has an atmosphere with $\sim 1.5 \% \mathrm{CH}_{4}$ derived entirely from abiotic sources. Titan also features a substantial haze layer, albeit derived from an $\mathrm{N}_{2}-\mathrm{CH}_{4}$ atmosphere, rather than the $\mathrm{CO}_{2}-\mathrm{CH}_{4}$ atmosphere we might expect for the early Earth, which may result in discernable differences in haze optical properties (Arney et al. 2016).

Surface biosignatures offer stronger evidence for life than atmospheric biosignatures, as there are currently no known false positives that precisely match the spectral characteristics of biological pigments. If we also consider surface reflectivity features, such as the vegetation "red edge," there exist a number of minerals that show a distinctive reflectivity transition similar to the "red edge," albeit at different wavelengths (Schwieterman et al. 2017). This suggests that, while they may be difficult to detect, pigments of surface communities may be the strongest biosignature (Schwieterman et al. 2017; Schwieterman this volume).

Lastly, the combined detection of several biosignatures, for example, $\mathrm{O}_{2}+$ $\mathrm{CH}_{4}$, could have an unusual, although unlikely, false positive. Observations of an unresolved binary planet system, with both bodies having abiotically generated atmospheres, but one oxidized (hosting the $\mathrm{O}_{2}$ signal) and one reduced (hosting the $\mathrm{CH}_{4}$ signal), could result in the simultaneous detection of $\mathrm{O}_{2}+\mathrm{CH}_{4}$ (Rein et al. 2014). This is an unlikely scenario, but it is still useful as a theoretical worstcase false positive. In order to rule out this false positive for life, the binary nature of the system would need to be confirmed, and the spectra from the two bodies disentangled (e.g. Agol et al. 2015; Li et al. 2016). Once this is done, the same treatment of potential false positives we apply to single-planet systems would be applied to each individual target.

\section{Seeing the Forest for the Not-Trees}

The identification of false positives for potential biosignatures is an important step in the search for life, as it allows us to look for associated environmental characteristics that would help us distinguish true from false positives. For potential biosignatures in the geologic record of the early Earth, a similar process has been used, and the analogy for Elephant Rock is apt; often, the identification of life is based on morphology, with later work adding chemical and isotopic data to better constrain biogenicity (i.e., its biological origin). Schopf et al. (2002) reported observing microbial filaments in the Apex Chert, identifying them visually, and verifying the presence of graphite, which is purportedly from altered kerogen (insoluble complex organic matter). However, later reanalysis showed this interpretation did not match the lithology, with the "fossil"-bearing section representing a breccia vein showing signs of repeated hydrothermal alterations (Brasier et al. 2002). This argument is still ongoing in the literature (Schopf and Kudryavtsev 2012; Brasier et al. 2015). Also within the Isua supracrustal belt, the Akilia island apatites were found to house 
isotopically light graphite (Mojzsis et al. 1996). However, follow-up work found no graphite associated with apatite crystals, even within the same initially reported sample (Lepland et al. 2005). Much like the biogenicity of the features within the Apex Chert, the origins of the carbon within the Akilia rocks are still debated (Papineau et al. 2010). Stepping away from fossil evidence for life on Earth, the famous Martian "microfossils" featured within the Allan Hills meteorite ALH84001 (McKay et al. 1996) could be the result of inorganic precipitation of carbonates at high temperature, which explains both the morphology and the anomalous ${ }^{13} \mathrm{C}$ enrichment (Golden et al. 2001, 2004).

Moving from the realm of confirmed false positives for geochemical and morphological biosignatures on Earth, we can imagine observing environmental and stellar characteristics when considering biosignatures on exoplanets. For at least two of the false positives associated with $\mathrm{O}_{2}$, a determination of the amount of $\mathrm{CO}_{2}$ in the planetary atmosphere is an important first step (Domagal-Goldman et al. 2014). $\mathrm{CO}_{2}$ photolysis rates sufficient to produce detectable amounts of $\mathrm{O}_{2}$ produce stoichiometric amounts of CO, which could be potentially detectable (Schwieterman et al. 2016; Wang et al. 2016). Determining the stellar near-UV-to-far-UV ratio would help constrain the provenance of the $\mathrm{O}_{2}$, in this case (Harman et al. 2015). In fact, the stellar near-UV-to-far-UV ratio may be obtained well in advance of the spectroscopic characterization of the exoplanet itself (e.g., France et al. 2013) or by the mission observing the exoplanet (France et al. 2017). Direct surface temperature retrievals would be more difficult (Des Marais et al. 2002) but not impossible (e.g., Maiolino et al. 2013; Brandl et al. 2014) and would provide valuable insight if available, in the absence of constraints on greenhouse gas concentrations (Forget and Leconte 2014). If not, then this would leave a degeneracy in determining the driving mechanism (whether the $\mathrm{O}_{2}$ is a result of a cold, dry planet, or one hosted by an $\mathrm{M}$ star). Constraints on atmospheric water vapor abundance are desirable to rule out $\mathrm{O}_{2}$ production in desiccated atmospheres (Gao et al. 2015), and water has several strong absorption features throughout the visible and near-infrared. This may also help identify planets orbiting host stars with long pre-main sequence lifetimes that have undergone significant water loss (Luger and Barnes 2015). For these planets, a natural consequence of large concentrations of $\mathrm{O}_{2}$ is the increasing presence of $\mathrm{O}_{2}$ collisionally induced absorption $\left(\mathrm{O}_{2}-\mathrm{O}_{2}\right.$, or $\left.\mathrm{O}_{4}\right)$, which is very sensitive to the partial pressure of $\mathrm{O}_{2}$ (Schwieterman et al. 2016). For the gentler water loss mechanism outlined by Wordsworth and Pierrehumbert (2014), measuring the amount of $\mathrm{N}_{2}$ directly is very difficult, but much like $\mathrm{O}_{2}$ there exists a spectrally active dimer $\left(\mathrm{N}_{2}-\mathrm{N}_{2}\right.$ or $\left.\mathrm{N}_{4}\right)$ which may be accessible near $4.2 \mu \mathrm{m}$, although this measurement is likely also challenging (Schwieterman et al. 2015b). Alternatively, this false positive could be ruled out by determining the presence of water vapor clouds in the planet's broadband continuum, or by looking for narrower atmospheric absorption for all features, due to the lower total atmospheric pressure expected for this mechanism.

For $\mathrm{N}_{2} \mathrm{O}$, given the paucity of potential false positives reported in the literature, we can imagine constraining the UV properties of the star, including extreme UV 
(XUV), near-UV, and far UV fluxes from the host star (Navarro et al. 2014). This would allow us to rule out whether a small abiotic source could supply enough $\mathrm{N}_{2} \mathrm{O}$ to overcome its photochemical sinks. On the other hand, the observation of $\mathrm{CH}_{4}$ by itself should not be considered a biosignature, even with an abundance of contextual information, in the absence of additional biosignatures like $\mathrm{O}_{2}$. For better or worse, the strongest single biosignature remains $\mathrm{O}_{2}$, even in the face of a larger catalog of potential false-positive mechanisms. However, the observation of multiple biosignatures can exclude a number of false-positive scenarios, as well as strengthen the case for life being present. Because $\mathrm{O}_{2}$ is currently the best potential biosignature for life on exoplanets, if we were to detect it in the atmosphere of an exoplanet, the amount of effort required to constrain the UV environment, as well as the abundances of $\mathrm{H}_{2} \mathrm{O}, \mathrm{CO}_{2}, \mathrm{~N}_{2}$, and $\mathrm{O}_{2}$, and the planet's cloud-coverage and total pressure, would be justified.

\section{Where the Rubber Meets the Road}

All these theories are a necessary step to apply our current understanding of biosignatures to the first opportunities we have to explore other worlds within and without our solar system. Future missions to Mars include the prospect of sample return (NRC 1997) and eventually, a human presence on the Red Planet (Levine and Schild 2010). This makes a firm understanding of biosignatures and contextual information from our own fossil record critical, especially when it comes to selection of the small number of samples we will return to Earth. For exoplanets, future large space- and ground-based observatories will offer us an unprecedented look at habitable and potentially inhabited worlds (e.g., Apai et al. 2017; Lovis et al. 2017; Morley et al. 2017; Snellen et al. 2017), potentially within the next 15 years (Fujii et al. 2017). How will these missions make the necessary measurements to validate biosignature detections?

For the detection of $\mathrm{O}_{2}$ as a biosignature and its discrimination from falsepositive cases, we will need (1) stellar UV measurements from at least Lyman-alpha ( $\sim 121.6 \mathrm{~nm}$; the strongest emission line for stars in the UV, driven by the first electronic transition of hydrogen) through to the visible ( 400 nm) and (2) observations of $\mathrm{CH}_{4}, \mathrm{CO}_{2}, \mathrm{H}_{2} \mathrm{O}, \mathrm{CO}, \mathrm{O}_{2}-\mathrm{O}_{2}$, and, if possible, $\mathrm{N}_{2}-\mathrm{N}_{2}$. The first, as previously mentioned, is underway for some planet-hosting systems already (France et al. 2013, 2016; Shkolnik and Barman 2014, and subsequent MUSCLES papers) or proposed (Shkolnik 2016). The second point, to observe planetary atmospheric composition, requires observations in the UV, visible, and infrared wavelengths. The strongest of these bands are at 7 to $8 \mu \mathrm{m}$ for $\mathrm{CH}_{4}, 9.6 \mu \mathrm{m}$ for $\mathrm{O}_{3}$, and the $15 \mu \mathrm{m}$ for $\mathrm{CO}_{2}$ band (Schwieterman et al. 2017; Fujii et al. 2017). However, high spectral resolution or direct imaging measurements with large space-based telescopes could detect these gases at near-infrared wavelengths, due to absorption features for $\mathrm{CH}_{4}$ at 1.8 and $2.4 \mu \mathrm{m}$, for $\mathrm{CO}_{2}$ (at high $\mathrm{CO}_{2}$ concentrations) at $1.1 \mu \mathrm{m}$, and for $\mathrm{CO}$ at $2.45 \mu \mathrm{m}$. 
JWST could potentially perform transmission spectroscopy all the way through the infrared, constraining most of these gases, with tens of transits for some of the nearest exoplanet systems (Morley et al. 2017). However, compared with groundbased telescope capabilities, JWST has only modest spectral resolution, which may push observations of less abundant biosignature and discriminator gases into the 2020s (Fujii et al. 2017). Ground-based telescopes like the VLT, using an adaptive optics system, in conjunction with a high-resolution spectrograph, would require up to 60 transits spread over 3 years but could look for $\mathrm{O}_{2}, \mathrm{H}_{2} \mathrm{O}$, and $\mathrm{CH}_{4}$ in Proxima Centauri b's atmosphere (Lovis et al. 2017). The extremely large telescopes (ELTs) coming online in the 2020s will be able to retrieve, at much higher spectral resolution, transmission spectroscopy of $\mathrm{CO}_{2}, \mathrm{O}_{2}$, and $\mathrm{H}_{2} \mathrm{O}$ in tens of transits as well, with the caveat that the limited field of view could be problematic (Fujii et al. 2017).

This next generation of ground-based telescopes could also detect and potentially characterize habitable planets via direct imaging using adaptive optics (Apai et al. 2017). And the next generation of flagship space-based telescopes is being designed from the start with a biosignature search, and elimination of false positives for those biosignatures, in mind. These missions - HabEx (Mennesson and Mawet 2016) and LUVOIR (France et al. 2015; Crooke et al. 2016) - will have both the UV capability required for host star characterization and starlight suppression to allow for direct imaging spectroscopy of potentially habitable planets. This will provide reflectedlight spectroscopy from $\sim 0.3 \mu \mathrm{m}$ to $\sim 1.8$ (for HabEx) or $\sim 2.5 \mu \mathrm{m}$ (for LUVOIR), including most of the false-positive discriminators. They should be able to detect $\mathrm{H}_{2} \mathrm{O}, \mathrm{O}_{2}$, and $\mathrm{O}_{3}$ on Earth-like worlds and sufficiently constrain the concentrations of $\mathrm{CH}_{4}, \mathrm{CO}$, and $\mathrm{CO}_{2}$ in order to eliminate known abiotic production mechanisms for $\mathrm{O}_{2}$ and $\mathrm{O}_{3}$.

Taken together, these observational techniques offer the unparalleled opportunity to find, characterize, and say with some certainty whether or not those worlds may host life. One potential approach is illustrated as a flow chart below (Fig. 4), allowing observers to selectively pursue further observations of those terrestrial planets with promising conditions or biosignatures. Right now, we have a limited catalog of Earth-sized exoplanets within their host stars' habitable zones, but future missions such as the Transiting Exoplanet Survey Satellite (TESS) and the CHaracterising ExOPlanet Satellite (CHEOPS) (Broeg et al. 2013; Ricker et al. 2014; Fujii et al. 2017), which are scheduled to launch in 2018, will add more. Continued advances in transit surveys and radial velocity instrumentation for ground-based telescopes will further add to the diversity of known planets with the potential for global biospheres (Meadows 2005). This suggests that, relatively soon, we may be able to pick only the most promising targets (i.e., those with the fewest potential for false positives) for more detailed follow-up studies. Although not as high a priority, we can also observe targets with higher potential for false-positive generation, as a test of the atmospheric and planetary science theories that predict their existence. 


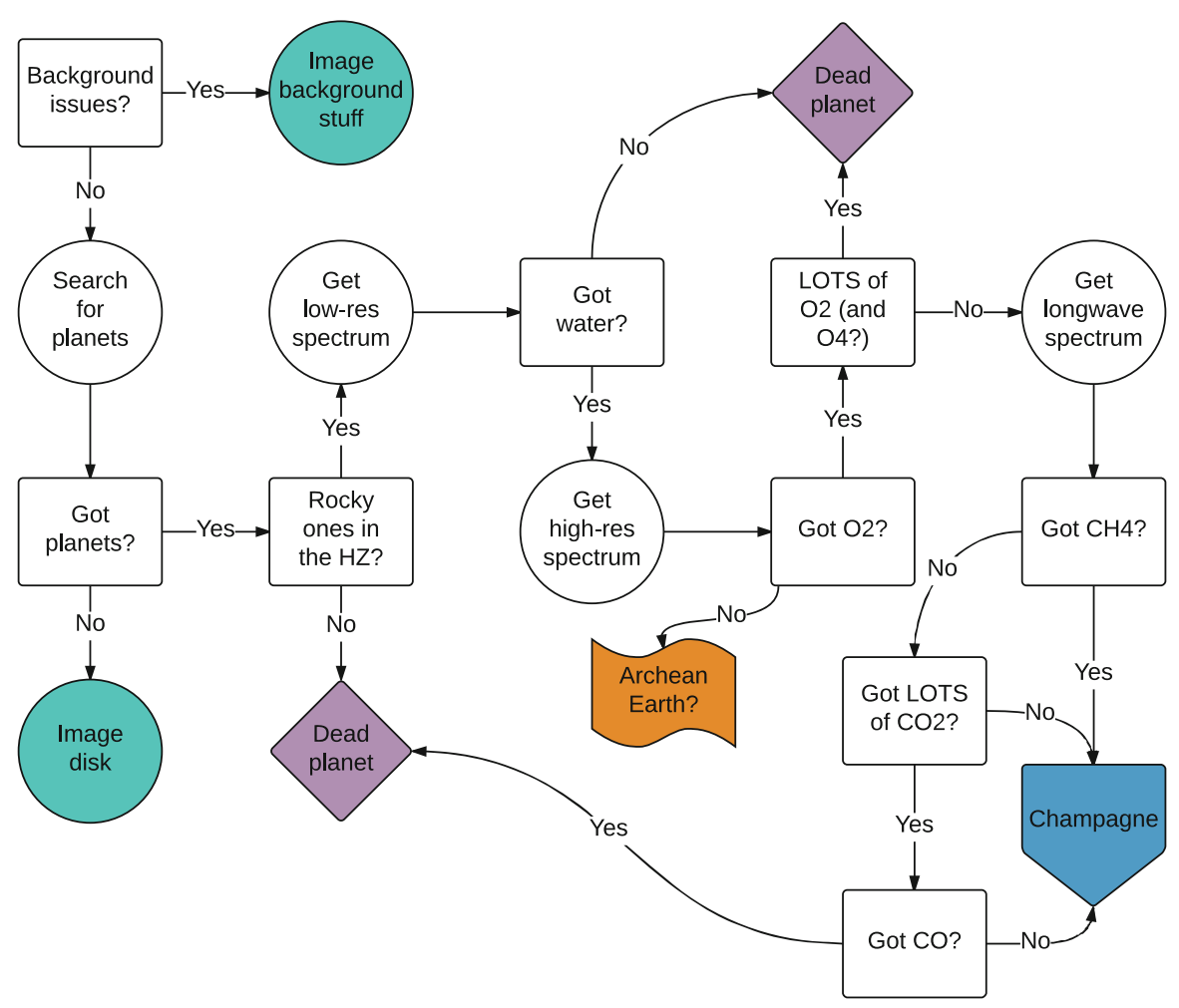

Fig. 4 Starting from the top left, this flow chart shows a plausible series of observations used to determine whether an extrasolar planet may harbor life. In this example, we are searching for surface photosynthetic life, as we have here on Earth, which takes in water and carbon dioxide $\left(\mathrm{CO}_{2}\right)$ and exhales molecular oxygen $\left(\mathrm{O}_{2}\right)$. Several measurements along the flow chart discriminate selected false-positive scenarios from the literature, as described in the text

\section{Conclusions}

With Kepler, we got our first glimpse behind the curtain, allowing us to begin to firmly ground our expectations for the prevalence of Earth-sized planets in the galaxy. Within the next few decades, our community will begin to unravel whether or not worlds other than our own may have life. Along the way, we are sure to face surprises - and potentially sensational false positives. In preparation for these observations, and our discovery announcements to the public, we should use our theoretical and practical understanding of planetary processes to predict as many "false positives" for life as possible. This will leverage lessons we have learned from the search for life in Earth's ancient rock record (c.f., Buick 1984) and prior claims of life on Mars (Levin and Straat 1977; McKay et al. 1996) that are not generally accepted by the science community. To paraphrase David Hume, a wise scientist weighs their convictions against the evidence or, as Carl 
Sagan popularized it, "extraordinary claims require extraordinary evidence." As such, the astrobiology community needs studies that tie the solid planet, potential biology, atmospheric chemistry and dynamics, and the host star together. This systems science approach will afford us the necessary expertise to diagnose false positives and validate any signs of life we may find elsewhere in the universe. Any biosignature without sufficient context is untrustworthy, and it is our responsibility to exhaust the alternatives (and heavily caveat the statement) before declaring that we have found life.

Acknowledgments The authors would like to acknowledge research support from the "ROCKE3D team" in the NASA's Nexus for Exoplanet System Science (NExSS), via solicitation NNH13ZDA017C, from the Habitable Worlds program via solicitation NNH15ZDA001NHW, and from the NASA Astrobiology Institute's Virtual Planetary Laboratory via solicitation NNH12ZDA002C. This chapter also benefited from Victoria Meadows' helpful comments.

\section{References}

Abeysekara AU, Archambault S, Archer A, Benbow W, Bird R, Buchovecky M, Buckley JH, Byrum K, Cardenzana JV, Cerruti M, Chen X (2016) A search for brief optical flashes associated with the SETI target KIC 8462852. Astrophys J Lett 818(2):33

Agol E, Jansen T, Lacy B, Robinson TD, Meadows V (2015) The center of light: spectroastrometric detection of exomoons. Astrophys J 812(1):5

Airapetian VS, Glocer A, Gronoff G, Hébrard E, Danchi W (2016) Prebiotic chemistry and atmospheric warming of early Earth by an active young Sun. Nat Geosci 9(6):452-455

Anglada-Escudé G, Amado PJ, Barnes J, Berdiñas ZM, Butler RP, Coleman GA, de La Cueva I, Dreizler S, Endl M, Giesers B, Jeffers SV (2016) A terrestrial planet candidate in a temperate orbit around Proxima Centauri. Nature 536(7617):437-440

Apai D, Cowan N, Kopparapu R, Kasper M, Hu R, Morley C, Fujii Y, Kane S, Maley M, del Genio A, Karalidi T (2017) Exploring other worlds: science questions for future direct imaging missions (EXOPAG SAG15 report). arXiv preprint arXiv:1708.02821

Arney G, Domagal-Goldman SD, Meadows VS, Wolf ET, Schwieterman E, Charnay B, Claire M, Hébrard E, Trainer MG (2016) The pale orange dot: the spectrum and habitability of hazy Archean Earth. Astrobiology 16(11):873-899

Baraffe I, Chabrier G, Allard F, Hauschildt P (1998) Evolutionary models for solar metallicity low-mass stars: mass-magnitude relationships and color-magnitude diagrams. Astron Astrophys 337:403-412

Brandl BR, Feldt M, Glasse A, Guedel M, Heikamp S, Kenworthy M, Lenzen R, Meyer MR, Molster F, Paalvast S, Pantin EJ (2014) METIS: the mid-infrared E-ELT imager and spectrograph. In: Proceedings of the SPIE ground-based and airborne instrumentation for astronomy, vol 9147, p 914721

Branduardi-Raymont G, Dunn WR, Sciortino S (2017) Future exoplanet research: XUV (EUV and X-ray) detection and characterization. In: Deeg H, Belmonte J (eds) Handbook of exoplanets. Springer, Cham

Brasier MD, Green OR, Jephcoat AP, Kleppe AK, Van Kranendonk MJ, Lindsay JF, Steele A, Grassineau NV (2002) Questioning the evidence for Earth's oldest fossils. Nature 416(6876):76-81

Brasier MD, Antcliffe J, Saunders M, Wacey D (2015) Changing the picture of Earth's earliest fossils $(3.5-1.9 \mathrm{Ga})$ with new approaches and new discoveries. Proc Natl Acad Sci 112(16):4859-4864 
Broeg C, Fortier A, Ehrenreich D, Alibert Y, Baumjohann W, Benz W, Deleuil M, Gillon M, Ivanov A, Liseau R, Meyer M (2013) CHEOPS: a transit photometry mission for ESA's small mission programme. In: Saglia R (ed) EPJ web of conferences, vol 47. Hot planets and cool stars, Garching. EDP Sciences. p 03005

Buick R (1984) Carbonaceous filaments from North Pole, Western Australia: are they fossil bacteria in Archaean stromatolites? Precambrian Res 24(2):157-172

Buick R (2007) Did the Proterozoic 'Canfield Ocean' cause a laughing gas greenhouse? Geobiology 5(2):97-100

Campbell B, Walker GA, Yang S (1988) A search for substellar companions to solar-type stars. Astrophys J 331:902-921

Cicerone RJ, Oremland RS (1988) Biogeochemical aspects of atmospheric methane. Glob Biogeochem Cycles 2(4):299-327

Cockell CS (2014) Habitable worlds with no signs of life. Phil Trans R Soc A 372(2014):20130082

Cooray AR, Origins Space Telescope Study Team (2017) Origins space telescope. In: American Astronomical Society meeting abstracts, vol 229

Crooke JA, Roberge A, Domagal-Goldman SD, Mandell AM, Bolcar MR, Rioux NM, Perez MR Smith EC (2016) Status and path forward for the large ultraviolet/optical/infrared surveyor (LUVOIR) mission concept study. In: Proceedings of the SPIE space telescopes and instrumentation 2016: optical, infrared, and millimeter wave, vol 9904, p 99044R

Deming D, Seager S, Winn J, Miller-Ricci E, Clampin M, Lindler D, Greene T, Charbonneau D, Laughlin G, Ricker G, Latham D (2009) Discovery and characterization of transiting super Earths using an all-sky transit survey and follow-up by the James Webb Space Telescope. Publ Astron Soc Pac 121(883):952

Des Marais DJ, Walter MR (1999) Astrobiology: exploring the origins, evolution, and distribution of life in the universe. Annu Rev Ecol Syst 30(1):397-420

Des Marais DJ, Harwit MO, Jucks KW, Kasting JF, Lin DN, Lunine JI, Schneider J, Seager S, Traub WA, Woolf NJ (2002) Remote sensing of planetary properties and biosignatures on extrasolar terrestrial planets. Astrobiology 2(2):153-181

Des Marais DJ, Nuth JA III, Allamandola LJ, Boss AP, Farmer JD, Hoehler TM, Jakosky BM, Meadows VS, Pohorille A, Runnegar B, Spormann AM (2008) The NASA astrobiology roadmap. Astrobiology 8(4):715-730

Dittmann JA, Irwin JM, Charbonneau D, Bonfils X, Astudillo-Defru N, Haywood RD, BertaThompson ZK, Newton ER, Rodriguez JE, Winters JG, Tan TG (2017) A temperate rocky super-Earth transiting a nearby cool star. Nature 544(7650):333

Domagal-Goldman SD, Kasting JF, Johnston DT, Farquhar J (2008) Organic haze, glaciations and multiple sulfur isotopes in the mid-Archean era. Earth Planet Sci Lett 269(1):29-40

Domagal-Goldman SD, Segura A, Claire MW, Robinson TD, Meadows VS (2014) Abiotic ozone and oxygen in atmospheres similar to prebiotic Earth. Astrophys J 792(2):90

Etiope G, Sherwood Lollar B (2013) Abiotic methane on Earth. Rev Geophys 51(2):276-299

Farquhar J, Zerkle AL, Bekker A (2011) Geological constraints on the origin of oxygenic photosynthesis. Photosynth Res 107(1):11-36

Forget F, Leconte J (2014) Possible climates on terrestrial exoplanets. Phil Trans R Soc A 372(2014):20130084

France K, Froning CS, Linsky JL, Roberge A, Stocke JT, Tian F, Bushinsky R, Désert JM, Mauas P, Vieytes M, Walkowicz LM (2013) The ultraviolet radiation environment around M dwarf exoplanet host stars. Astrophys J 763(2):149

France K, Shkolnik E, Linsky J, Roberge A, Ayres T, Barman T, Brown A, Davenport J, Desert JM, Domagal-Goldman S, Fleming B (2015) Characterizing the habitable zones of exoplanetary systems with a large ultraviolet/visible/near-IR space observatory. arXiv preprint arXiv: 1505.01840

France K, Loyd RP, Youngblood A, Brown A, Schneider PC, Hawley SL, Froning CS, Linsky JL, Roberge A, Buccino AP, Davenport JR (2016) The MUSCLES treasury survey. I. Motivation and overview. Astrophys J 820(2):89 
France K, Fleming B, West G, McCandliss SR, Bolcar MR, Harris W, Moustakas L, O’Meara JM, Pascucci I, Rigby J, Schiminovich D (2017) The LUVOIR ultraviolet multi-object spectrograph (LUMOS): instrument definition and design. In: UV, X-ray, and gamma-ray space instrumentation for astronomy XX, vol 10397. International Society for Optics and Photonics, p 1039713

Fujii Y, Angerhausen D, Deitrick R, Domagal-Goldman S, Grenfell JL, Hori Y, Palle E, Siegler N, Stapelfeldt K, Rauer H (2017) Exoplanet biosignatures: observational prospects. arXiv preprint arXiv: 1705.07098

Gao P, Hu R, Robinson TD, Li C, Yung YL (2015) Stability of $\mathrm{CO}_{2}$ atmospheres on desiccated M dwarf exoplanets. Astrophys J 806(2):249

Garcia-Sage K, Glocer A, Drake JJ, Gronoff G, Cohen O (2017) On the magnetic protection of the atmosphere of Proxima Centauri b. Astrophys J Lett 844(1):13

Gaskin JA, Allured R, Bandler SR, Basso S, Bautz MW, Baysinger MF, Biskach MP, Boswell TM, Capizzo PD, Chan K, Civitani MM, Cohen LM, Cotroneo V, Davis JM, DeRoo CT, DiPirro MJ, Dominguez A, Fabisinski LL, Falcone AD, Figueroa-Feliciano E, Garcia JC, Gelmis KE, Heilmann RK, Hopkins RC, Jackson T, Kilaru K, Kraft RP, Liu T, McClelland RS, McEntaffer RL, McCarley KS, Mulqueen JA, Özel F, Pareschi G, Reid PB, Riveros RE, Rodriguez MA, Rowe JW, Saha TT, Schattenburg ML, Schnell AR, Schwartz DA, Solly PM, Suggs RM, Sutherlin SG, Swartz DA, Trolier-McKinstry S, Tutt JH, Vikhlinin A, Walker J, Yoon W, Zhang WW (2017) Lynx Mission concept status. In: Proceedings of the SPIE 10397, UV, X-ray, and gamma-ray space instrumentation for astronomy XX, 103970S

Gates DM, Keegan HJ, Schleter JC, Weidner VR (1965) Spectral properties of plants. Appl Opt 4(1):11-20

Gebauer S, Grenfell JL, Stock JW, Lehmann R, Godolt M, von Paris P, Rauer H (2017) Evolution of Earth-like extrasolar planetary atmospheres: assessing the atmospheres and biospheres of early Earth analog planets with a coupled atmosphere biogeochemical model. Astrobiology 17(1):27-54

Gillon M, Jehin E, Lederer SM, Delrez L, de Wit J, Burdanov A, Van Grootel V, Burgasser AJ, Triaud AH, Opitom C, Demory BO (2016) Temperate Earth-sized planets transiting a nearby ultracool dwarf star. Nature 533(7602):221-224

Golden DC, Ming DW, Schwandt CS, Lauer HV, Socki RA, Morris RV, Lofgren GE, McKay GA (2001) A simple inorganic process for formation of carbonates, magnetite, and sulfides in Martian meteorite ALH84001. Am Mineral 86(3):370-375

Golden DC, Ming DW, Morris RV, Brearley AJ, Lauer HV, Treiman AH, Zolensky ME, Schwandt CS, Lofgren GE, McKay GA (2004) Evidence for exclusively inorganic formation of magnetite in Martian meteorite ALH84001. Am Mineral 89(5-6):681-695

Guzmán-Marmolejo A, Segura A, Escobar-Briones E (2013) Abiotic production of methane in terrestrial planets. Astrobiology 13(6):550-559

Haqq-Misra JD, Domagal-Goldman SD, Kasting PJ, Kasting JF (2008) A revised, hazy methane greenhouse for the Archean Earth. Astrobiology 8(6):1127-1137

Harman CE, Kasting JF, Wolf ET (2013) Atmospheric production of glycolaldehyde under hazy prebiotic conditions. Orig Life Evol Biosph 43(2):77-98

Harman CE, Schwieterman EW, Schottelkotte JC, Kasting JF (2015) Abiotic $\mathrm{O}_{2}$ levels on planets around F, G, K, and M stars: possible false positives for life? Astrophys J 812(2):137

Hegde S, Paulino-Lima IG, Kent R, Kaltenegger L, Rothschild L (2015) Surface biosignatures of exo-Earths: remote detection of extraterrestrial life. Proc Natl Acad Sci 112(13):3886-3891

Hitchcock DR, Lovelock JE (1967) Life detection by atmospheric analysis. Icarus 7(1-3):149-159

Izon G, Zerkle AL, Williford KH, Farquhar J, Poulton SW, Claire MW (2017) Biological regulation of atmospheric chemistry en route to planetary oxygenation. Proc Natl Acad Sci 114(13):E2571-E2579

Kaltenegger L, Traub WA, Jucks KW (2007) Spectral evolution of an Earth-like planet. Astrophys J 658(1):598

Kasting JF (1995) $\mathrm{O}_{2}$ concentrations in dense primitive atmospheres: commentary. Planet Space Sci 43(1-2):11-13 
Kasting JF (1997) Habitable zones around low mass stars and the search for extraterrestrial life. OLEB 27(1-3):291-307

Kasting JF (2005) Methane and climate during the Precambrian era. Precambrian Res 137(3):119129

Kasting JF (2010) How to find a habitable planet. Princeton University Press, Princeton

Kasting JF, Canfield DE (2012) The global oxygen cycle. In: Knoll AH, Canfield DE, Konhauser KO (eds) Fundamentals of geobiology. Wiley, Chichester

Kasting JF, Pollack JB, Crisp D (1984) Effects of high $\mathrm{CO}_{2}$ levels on surface temperature and atmospheric oxidation state of the early Earth. J Atmos Chem 1(4):403-428

Kasting JF, Whitmire DP, Reynolds RT (1993) Habitable zones around main sequence stars. Icarus 101(1):108-128

Kawahara H, Matsuo T, Takami M, Fujii Y, Kotani T, Murakami N, Tamura M, Guyon O (2012) Can ground-based telescopes detect the oxygen $1.27 \mu \mathrm{m}$ absorption feature as a biomarker in exoplanets? Astrophys J 758(1):13

Kharecha P, Kasting J, Siefert J (2005) A coupled atmosphere-ecosystem model of the early Archean Earth. Geobiology 3(2):53-76

Kirschke S, Bousquet P, Ciais P, Saunois M, Canadell JG, Dlugokencky EJ, Bergamaschi P, Bergmann D, Blake DR, Bruhwiler L, Cameron-Smith P (2013) Three decades of global methane sources and sinks. Nat Geosci 6(10):813-823

Kopparapu RK, Ramirez R, Kasting JF, Eymet V, Robinson TD, Mahadevan S, Terrien RC, Domagal-Goldman S, Meadows V, Deshpande R (2013) Habitable zones around main-sequence stars: new estimates. Astrophys J 765(2):131

Krissansen-Totton J, Bergsman DS, Catling DC (2016) On detecting biospheres from chemical thermodynamic disequilibrium in planetary atmospheres. Astrobiology 16(1):39-67

Kump LR (2008) The rise of atmospheric oxygen. Nature 451(7176):277

Lepland A, van Zuilen MA, Arrhenius G, Whitehouse MJ, Fedo CM (2005) Questioning the evidence for Earth's earliest life - Akilia revisited. Geology 33(1):77-79

Levin GV, Straat PA (1977) Recent results from the Viking labeled release experiment on Mars. J Geophys Res 82(28):4663-4667

Levine JS, Schild RE (eds) (2010) The human mission to Mars: colonizing the red planet. Cosmology Science Publishers, Cambridge, MA

Li T, Tian F, Wang Y, Wei W, Huang X (2016) Distinguishing a hypothetical abiotic planet-moon system from a single inhabited planet. Astrophys J Lett 817(2):L15

Lippincott ER, Eck RV, Dayhoff MO, Sagan C (1967) Thermodynamic equilibria in planetary atmospheres. Astrophys J 147:753

Lovelock JE, Kaplan IR (1975) Thermodynamics and the recognition of alien biospheres. Proc R Soc Lond B Biol Sci 189:167-181

Lovis C, Snellen I, Mouillet D, Pepe F, Wildi F, Astudillo-Defru N, Beuzit JL, Bonfils X, Cheetham A, Conod U, Delfosse X (2017) Atmospheric characterization of Proxima b by coupling the SPHERE high-contrast imager to the ESPRESSO spectrograph. Astron Astrophys 599:16

Luger R, Barnes R (2015) Extreme water loss and abiotic $\mathrm{O}_{2}$ buildup on planets throughout the habitable zones of M dwarfs. Astrobiology 15(2):119-143

Lyons TW, Reinhard CT, Planavsky NJ (2014) The rise of oxygen in Earth's early ocean and atmosphere. Nature 506(7488):307-315

Maiolino R, Haehnelt M, Murphy MT, Queloz D, Origlia L, Alcala J, Alibert Y, Amado PJ, Prieto CA, Eiff M, Asplund M (2013) A community science case for E-ELT HIRES. arXiv preprint arXiv: 1310.3163

Mayor M, Queloz D (1995) A Jupiter-mass companion to a solar-type star. Nature 378:355-359

McKay DS, Gibson EK Jr, Thomas-Keprta KL, Vali H (1996) Search for past life on Mars: possible relic biogenic activity in Martian meteorite ALH84001. Science 273(5277):924

Meadows VS (2005) Modelling the diversity of extrasolar terrestrial planets. Proc Int Astron Union 1(C200):25-34

Meadows VS (2017) Reflections on $\mathrm{O}_{2}$ as a biosignature in exoplanetary atmospheres. Astrobiology 17(10):1022-1052 
Meadows VS, Reinhard CT, Arney GN, Parenteau MN, Schwieterman EW, Domagal-Goldman SD, Lincowski AP, Stapelfeldt KR, Rauer H, DasSarma S, Hegde S (2017) Exoplanet biosignatures: understanding oxygen as a biosignature in the context of its environment. arXiv preprint arXiv: 1705.07560

Mennesson B, Mawet D (2016) The habitable exoplanet (HabEx) imaging mission: preliminary science drivers and technical requirements. Society of Photo-Optical Instrumentation Engineers (SPIE), Bellingham

Mojzsis SJ, Arrhenius G, McKeegan KD, Harrison TM, Nutman AP, Friend CRL (1996) Evidence for life on Earth before 3,800 million years ago. Nature 384(6604):55

Morley CV, Kreidberg L, Rustamkulov Z, Robinson T Fortney JJ (2017) Observing the atmospheres of known temperate Earth-sized planets with JWST. Astrophys J 850(2):121

Navarro KF, Navarro-Gonzalez R, McKay CP (2014) Abiotic production of nitrous oxide by lightning. Implications for a false positive identification of life on Earth-like planets around quiescent M dwarfs. In: 40th COSPAR scientific assembly, vol 40

National Research Council (1997) Mars sample return: issues and recommendations. The National Academies Press, Washington, DC. https://doi.org/10.17226/5563

Ohtomo Y, Kakegawa T, Ishida A, Nagase T, Rosing MT (2014) Evidence for biogenic graphite in early Archaean Isua metasedimentary rocks. Nat Geosci 7(1):25

Papineau D (2010) Mineral environments on the earliest Earth. Elements 6(1):25-30

Papineau D, De Gregorio BT, Cody GD, Fries MD, Mojzsis SJ, Steele A, Stroud RM, Fogel ML (2010) Ancient graphite in the Eoarchean quartz-pyroxene rocks from Akilia in southern West Greenland I: petrographic and spectroscopic characterization. Geochim Cosmochim Acta 74(20):5862-5883

Pavlov AA, Hurtgen MT, Kasting JF, Arthur MA (2003) Methane-rich Proterozoic atmosphere? Geology 31(1):87-90

Pilcher CB (2003) Biosignatures of early earths. Astrobiology 3(3):471-486

Planavsky NJ, Reinhard CT, Wang X, Thomson D, McGoldrick P, Rainbird RH, Johnson T, Fischer WW, Lyons TW (2014) Low mid-Proterozoic atmospheric oxygen levels and the delayed rise of animals. Science 346(6209):635-638

Quintana EV, Barclay T, Raymond SN, Rowe JF, Bolmont E, Caldwell DA, Howell SB, Kane SR, Huber D, Crepp JR, Lissauer JJ (2014) An Earth-sized planet in the habitable zone of a cool star. Science 344(6181):277-280

Rein H, Fujii Y, Spiegel DS (2014) Some inconvenient truths about biosignatures involving two chemical species on Earth-like exoplanets. Proc Natl Acad Sci 111(19):6871-6875

Reinhard CT, Olson SL, Schwieterman EW, Lyons TW (2017) False negatives for remote life detection on ocean-bearing planets: lessons from the early Earth. Astrobiology 17(4):287-297

Ricker GR, Vanderspek RK, Latham DW, Winn JN (2014) The transiting exoplanet survey satellite mission. In: American Astronomical Society meeting abstracts\# 224, vol 224

Roberson AL, Roadt J, Halevy I, Kasting JF (2011) Greenhouse warming by nitrous oxide and methane in the Proterozoic Eon. Geobiology 9(4):313-320

Robinson TD, Meadows VS, Crisp D, Deming D, A'Hearn MF, Charbonneau D, Livengood TA, Seager S, Barry RK, Hearty T, Hewagama T (2011) Earth as an extrasolar planet: Earth model validation using EPOXI Earth observations. Astrobiology 11(5):393-408

Rodler F, López-Morales M (2014) Feasibility studies for the detection of $\mathrm{O}_{2}$ in an Earth-like exoplanet. Astrophys J 781(1):54

Rosing MT (1999) 13C-depleted carbon microparticles in> 3700-Ma sea-floor sedimentary rocks from West Greenland. Science 283(5402):674-676

Rugheimer S, Kaltenegger L, Zsom A, Segura A, Sasselov D (2013) Spectral fingerprints of Earthlike planets around FGK stars. Astrobiology 13(3):251-269

Rugheimer S, Kaltenegger L, Segura A, Linsky J, Mohanty S (2015) Effect of UV radiation on the spectral fingerprints of Earth-like planets orbiting M stars. Astrophys J 809(1):57

Rye R, Holland HD (2000) Life associated with a 2.76 Ga ephemeral pond?: evidence from Mount Roe \#2 paleosol. Geology 28(6):483-486 
Sagan C, Thompson WR, Carlson R, Gurnett D, Hord C (1993) A search for life on Earth from the Galileo spacecraft. Nature 365(6448):715

Samarkin VA, Madigan MT, Bowles MW, Casciotti KL, Priscu JC, McKay CP, Joye SB (2010) Abiotic nitrous oxide emission from the hypersaline Don Juan Pond in Antarctica. Nat Geosci 3(5):341-344

Schindler TL, Kasting JF (2000) Synthetic spectra of simulated terrestrial atmospheres containing possible biomarker gases. Icarus 145(1):262-271

Schopf JW, Kudryavtsev AB (2012) Biogenicity of Earth's earliest fossils: a resolution of the controversy. Gondwana Res 22(3):761-771

Schopf JW, Kudryavtsev AB, Agresti DG, Wdowiak TJ, Czaja AD (2002) Laser-Raman imagery of Earth's earliest fossils. Nature 416(6876):73-76

Schumann U, Huntrieser H (2007) The global lightning-induced nitrogen oxides source. Atmos Chem Phys 7(14):3823-3907

Schwieterman EW, Cockell CS, Meadows VS (2015a) Nonphotosynthetic pigments as potential biosignatures. Astrobiology 15(5):341-361

Schwieterman EW, Robinson TD, Meadows VS, Misra A, Domagal-Goldman S (2015b) Detecting and constraining $\mathrm{N}_{2}$ abundances in planetary atmospheres using collisional pairs. Astrophys $\mathrm{J}$ 810(1):57

Schwieterman EW, Meadows VS, Domagal-Goldman SD, Deming D, Arney GN, Luger R, Harman CE, Misra A, Barnes R (2016) Identifying planetary biosignature impostors: spectral features of $\mathrm{CO}$ and $\mathrm{O}_{4}$ resulting from abiotic $\mathrm{O}_{2} / \mathrm{O}_{3}$ production. Astrophys J Lett 819(1):13

Schwieterman EW, Kiang NY, Parenteau MN, Harman CE, DasSarma S, Fisher TM, Arney GN, Hartnett HE, Reinhard CT, Olson SL, Meadows VS (2017) Exoplanet biosignatures: a review of remotely detectable signs of life. arXiv preprint arXiv:1705.05791

Seager S, Turner EL, Schafer J, Ford EB (2005) Vegetation's red edge: a possible spectroscopic biosignature of extraterrestrial plants. Astrobiology 5(3):372-390

Segura A, Krelove K, Kasting JF, Sommerlatt D, Meadows V, Crisp D, Cohen M, Mlawer E (2003) Ozone concentrations and ultraviolet fluxes on Earth-like planets around other stars. Astrobiology 3(4):689-708

Segura A, Kasting JF, Meadows V, Cohen M, Scalo J, Crisp D, Butler RA, Tinetti G (2005) Biosignatures from Earth-like planets around M dwarfs. Astrobiology 5(6):706-725

Segura A, Meadows VS, Kasting JF, Crisp D, Cohen M (2007) Abiotic formation of $\mathrm{O}_{2}$ and $\mathrm{O}_{3}$ in high- $\mathrm{CO}_{2}$ terrestrial atmospheres. Astron Astrophys 472(2):665-679

Shkolnik E (2016) HAZMAT: habitable zones and M dwarf activity across time. HST Proposal

Shkolnik EL, Barman TS (2014) HAZMAT. I. The evolution of far-UV and near-UV emission from early M stars. Astron J 148(4):64

Shostak S, Oliver C (2000) Immediate reaction plan: a strategy for dealing with a SETI detection. In: Bioastronomy 99, vol 213

Snellen IAG, de Kok RJ, Le Poole R, Brogi M, Birkby J (2013) Finding extraterrestrial life using ground-based high-dispersion spectroscopy. Astrophys J 764(2):182

Snellen I, de Kok R, Birkby JL, Brandl B, Brogi M, Keller C, Kenworthy M, Schwarz H, Stuik $\mathrm{R}$ (2015) Combining high-dispersion spectroscopy with high contrast imaging: probing rocky planets around our nearest neighbors. Astron Astrophys 576:A59

Snellen IAG, Désert JM, Waters LBFM, Robinson T, Meadows V, van Dishoeck EF, Brandl BR, Henning T, Bouwman J, Lahuis F, Min M (2017) Detecting Proxima b's atmosphere with JWST targeting $\mathrm{CO}_{2}$ at $15 \mu \mathrm{m}$ using a high-pass spectral filtering technique. Astron J 154(77):8

Spergel D, Gehrels N, Baltay C, Bennett D, Breckinridge J, Donahue M, Dressler A, Gaudi BS, Greene T, Guyon O, Hirata C (2015) Wide-field infrared survey telescope-astrophysics focused telescope assets WFIRST-AFTA 2015 report. arXiv preprint arXiv:1503.03757

Tarter J (2001) The search for extraterrestrial intelligence (SETI). Annu Rev Astron Astrophys 39(1):511-548

Tarter JC, Agrawal A, Ackermann R, Backus P, Blair SK, Bradford MT, Harp GR, Jordan J, Kilsdonk T, Smolek KE, Richards J (2010) SETI turns 50: five decades of progress in the search for extraterrestrial intelligence. Proc SPIE Instrum Methods Missions Astrobiol XIII 7819:781902-781901 
Thomas-Keptra KL, Clemett SJ, Wentworth SJ, McKay DS Gibson Jr EK (2010) New insights into the origin of magnetite crystals in ALH84001 carbonate disks. In: Astrobiology science conference 2010, League City

Tian F, France K, Linsky JL, Mauas PJ, Vieytes MC (2014) High stellar FUV/NUV ratio and oxygen contents in the atmospheres of potentially habitable planets. Earth Planet Sci Lett 385:22-27

Turnbull MC, Traub WA, Jucks KW, Woolf NJ, Meyer MR, Gorlova N, Skrutskie MF, Wilson JC (2006) Spectrum of a habitable world: earthshine in the near-infrared. Astrophys J 644(1):551

Twicken JD, Jenkins JM, Seader SE, Tenenbaum P, Smith JC, Brownston LS, Burke CJ, Catanzarite JH, Clarke BD, Cote MT, Girouard FR (2016) Detection of potential transit signals in 17 quarters of Kepler data: results of the final Kepler mission transiting planet search (DR25). Astron J 152(6): 158

Wang Y, Tian F, Li T, Hu Y (2016) On the detection of carbon monoxide as an anti-biosignature in exoplanetary atmospheres. Icarus 266:15-23

Warner MJ, Bullister JL, Wisegarver DP, Sonnerup RE, Chang BX (2016) A Baseline for monitoring long-term changes in the global distribution of $\mathrm{N}_{2} \mathrm{O}$ in the ocean. In: AGU fall meeting abstracts

Watanabe Y, Martini JE, Ohmoto H (2000) Geochemical evidence for terrestrial ecosystems 2.6 billion years ago. Nature 408(6812):574

Welch J, Backer D, Blitz L, Bock DCJ, Bower GC, Cheng C, Croft S, Dexter M, Engargiola G, Fields E, Forster J (2009) The Allen telescope array: the first widefield, panchromatic, snapshot radio camera for radio astronomy and SETI. Proc IEEE 97(8):1438-1447

Wolszczan A, Frail DA (1992) A planetary system around the millisecond pulsar PSR1257+12. Nature 355(6356): 145

Wordsworth R, Pierrehumbert R (2014) Abiotic oxygen-dominated atmospheres on terrestrial habitable zone planets. Astrophys J Lett 785(2):20

Zerkle AL, Claire MW, Domagal-Goldman SD, Farquhar J, Poulton SW (2012) A bistable organicrich atmosphere on the Neoarchaean Earth. Nat Geosci 5(5):359 